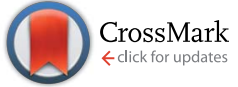

Cite this: RSC Adv., 2017, 7, 9764

\title{
Heavy metals removal by EDTA-functionalized chitosan graphene oxide nanocomposites $\uparrow$
}

\author{
Asif Shahzad, ${ }^{a}$ Waheed Miran, ${ }^{a}$ Kashif Rasool, ${ }^{\mathrm{b}}$ Mohsin Nawaz, ${ }^{\mathrm{a}}$ Jiseon Jang, ${ }^{\mathrm{a}}$ \\ Seong-Rin Lim ${ }^{\star c}$ and Dae Sung Lee*a
}

Graphene-based two-dimensional materials have been explored in a variety of applications, including the treatment of heavy-metal-rich water/wastewater. Ethylenediaminetetraacetic acid (EDTA)-functionalized magnetic chitosan (CS) graphene oxide (GO) nanocomposites (EDTA-MCS/GO) were synthesized using a reduction precipitation method and applied to the removal of heavy metals, such as $\mathrm{Pb}^{2+}, \mathrm{Cu}^{2+}$, and $\mathrm{As}^{3+}$, from aqueous solutions. The synthesized nanocomposite was characterized by FT-IR, XRD, SEM, MPMS, zeta-potential and BET analyses. The influence of various operating parameters, such as $\mathrm{pH}$, temperature, metal ion concentration, and contact time on the removal of the metal ions, was investigated. Owing to the large specific surface area, hydrophilic behavior, and functional moieties, the magnetic nanocomposite demonstrated excellent removal ability with a maximum adsorption capacity of 206.52, 207.26, and $42.75 \mathrm{mg} \mathrm{g}^{-1}$ for $\mathrm{Pb}^{2+}, \mathrm{Cu}^{2+}$, and $\mathrm{As}^{3+}$, respectively. The equilibrium data was evaluated by Langmuir and Freundlich isotherms, while the heavy metal adsorption reaction kinetics was analyzed by Lagergren pseudo-first-order and pseudo-second-order kinetic models. The nanocomposite was reused in four successive adsorption-desorption cycles, revealing a good regeneration capacity of the adsorbent.

Received 19th December 2016
Accepted 25th January 2017

DOI: $10.1039 / c 6 r a 28406 j$

rsc.li/rsc-advances muscular weakness, loss of appetite, and nausea. ${ }^{7,8}$ Therefore, heavy metals are important environmental concerns with adverse links to human health and the economy. ${ }^{9}$ These issues require effective treatment of heavy-metal-rich wastewater to decrease pollutants to acceptable levels.

In this regard, many techniques have been developed for the removal of heavy metals from wastewater, such as chemical precipitation, ion exchange, reverse osmosis, membrane filtration, electrolysis, and adsorption. Among these, adsorption is the preferred technology because of its simplicity, effectiveness, and low cost in the removal of toxic heavy metals from water/ wastewater. ${ }^{10}$ Moreover, the simple operation, time efficiency, and large-scale applicability of the adsorption method are considered promising for the development of wastewater treatment technologies. In recent years, carbonaceous nanomaterials such as graphene oxide (GO), a two- or threedimensional nanosheet, have attracted the attention of researchers because of their unique properties and large composition diversity. The presence of a wide range of consecutive oxygen functional groups on the GO surface and large surface area are characteristics that make GO an excellent adsorbent for the removal of heavy metals and several other pollutants. ${ }^{11}$ Moreover, the large specific surface area of GO provides abundant attachment sites for the functionalization of other compounds, such as chitosan (CS) and ethylenediaminetetraacetic acid (EDTA). This can ultimately increase the number of surface functional groups, which might enhance heavy metal adsorption. CS with primary amino groups is easily
${ }^{a}$ Department of Environmental Engineering, Kyungpook National University, 80 Daehak-ro, Buk-gu, Daegu 41566, Republic of Korea. E-mail: daesung@knu.ac.kr; Fax: +82-53-950-6579; Tel: +82-53-953-7286

${ }^{b}$ Qatar Environment and Energy Research Institute, Hamad Bin Khalifa University, Qatar Foundation, Doha, Qatar

'Department of Environmental Engineering, Kangwon National University, Chuncheon, Gangwon, South Korea.E-mail: srlim@kangwon.ac.kr.

$\dagger$ Electronic supplementary information (ESI) available. See DOI: 10.1039/c6ra28406j 
functionalized with different organic ligands, such as GO and EDTA, to improve its adsorption capacity. EDTA has many applications, including as a dyeing auxiliary, stabilizer, softener, and in coordination titration. ${ }^{12}$ In previous studies, EDTA chelation with divalent metals has been reported, in which one carboxyl group is freely available and one water molecule is coordinated to the metal center. ${ }^{12,13}$ Therefore, EDTA is a good candidate for the adsorption of heavy metals and can be functionalized with other materials such as GO and CS. Many nanomaterials, functionalized with EDTA and CS, have been reported and they showed significant adsorption behaviors towards divalent heavy metals such as $\mathrm{Co}, \mathrm{Hg}$, and $\mathrm{Cu}$ in aqueous solution. . $^{12,13}$ However, it is necessary to develop a novel material which can remove both divalent heavy metals and trivalent ones such as $\mathrm{As}^{3+}$ from drinking water as well as from industrial wastewater.

In this study, EDTA-functionalized magnetic chitosan graphene oxide (EDTA-MCS/GO) nanocomposites are synthesized using a reduction precipitation method. ${ }^{14}$ This preparation method is inexpensive, rapid and does not require reactive gases or toxic cross-linking agents. The method can proceed at room temperature, thus representing a significant improvement over previously available synthetic methods. ${ }^{15}$ Magnetic properties were also incorporated into the nanocomposites to allow the used absorbent to be easily retrieved from an aqueous solution after the adsorption of heavy metals. The adsorption behavior of synthesized EDTA-MCS/GO nanocomposites was investigated for divalent $\mathrm{Pb}^{2+}, \mathrm{Cu}^{2+}$, and trivalent $\mathrm{As}^{3+}$ ions in aqueous solution.

\section{Experimental work}

\subsection{Synthesis of EDTA-MCS/GO}

GO was synthesized using a modified Hummers' method. ${ }^{16}$ The synthesis of EDTA-MCS/GO was a two-step process. In the first step, $\mathrm{FeCl}_{3} \cdot 6 \mathrm{H}_{2} \mathrm{O}(1.22 \mathrm{~g})$ was dispersed in $\mathrm{HCl}(35.0 \mathrm{~mL}, 0.1 \mathrm{M})$. CS $(2.0 \%)$ solution was obtained by dissolving low weight CS in $1.0 \%$ HCl. GO (15.0 mL, $0.33 \mathrm{wt} \%)$ solution, CS $(2.5 \mathrm{~mL}, 2.0$ wt\%) solution, and distilled water $(7.5 \mathrm{~mL})$ were added together and vigorously stirred for $1 \mathrm{~h}$ at room temperature. Later, produced $\mathrm{FeCl}_{3}$ solution and $\mathrm{Na}_{2} \mathrm{SO}_{3}(15 \mathrm{~mL}, 0.19 \mathrm{~g})$ solution were added to the mixture with continuous stirring for $30 \mathrm{~min}$, resulting in a solution color change from brownish to blackish. Then, $\mathrm{NH}_{3}(16.0 \mathrm{~mL}, 14 \%)$ was added to induce the precipitation of a blackish material. The obtained product (MCS/GO) was washed several times with DI water and absolute ethanol, and finally dried in an oven at $60{ }^{\circ} \mathrm{C}$. In the second step, $\mathrm{Na}_{2}$ EDTA ( $45 \mathrm{~mL}, 13.3 \mathrm{wt} \%$ ) and dried ground MCS/GO (20 mL, $5.0 \mathrm{wt} \%$ ) dispersions were mixed and allowed to react for $24 \mathrm{~h}$ at room temperature. The resultant product (EDTA-MCS/GO) was separated using a magnet and purified by washing several times with DI water and absolute ethanol. Finally, the synthesized EDTAMCS/GO nanocomposite was oven dried at $60{ }^{\circ} \mathrm{C}$ then manually grinded into a fine powder for adsorption studies.

\subsection{Characterization of EDTA-MCS/GO}

Fourier transform infrared (FT-IR) spectroscopy, X-ray diffraction (XRD), scanning electron microscopy (SEM), magnetic property measurement system (MPMS), zeta-potential and Brunauer-Emmett-Teller (BET) measurements were used to characterize the synthesized EDTA-MCS/GO nanocomposite. The FT-IR spectrum was recorded in the spectral range 4000$400 \mathrm{~cm}^{-1}$ on an FT-IR spectrometer (Perkin-Elmer, USA). XRD was performed using an X-ray diffractometer (D/Max-2500, Rigaku) with $\mathrm{Cu} \mathrm{K} \alpha$ radiation $(\lambda=1.5406 \AA)$ in the scanning range $0-80^{\circ}(2 \mathrm{~h})$. SEM (HITACHI S-4800, Japan) was used to obtain micro-level features of EDA-MCS/GO. For MPMS analysis, MPMS SQUID VSM (Quantum Design Inc. USA) was used and zeta-potential values were measured using Zetasizer Nano ZS (Malvern Instruments). Nitrogen gas adsorption-desorption onto EDTA-MCS/GO was performed to evaluate the nanocomposite BET surface area (Quantachrome version-5.04, America).

\subsection{Adsorption experiments}

In order to study the adsorption behaviors of heavy metals onto the synthesized EDTA-MCS/GO nanocomposites, batch adsorption experiments were conducted. The $\mathrm{Pb}^{2+}, \mathrm{Cu}^{2+}$, and $\mathrm{As}^{3+}$ sources were $\mathrm{PbCl}_{2}, \mathrm{Cu}_{2}\left(\mathrm{NO}_{3}\right)_{2} \cdot 3 \mathrm{H}_{2} \mathrm{O}$, and $\mathrm{As}_{2} \mathrm{O}_{3}$, respectively. $\mathrm{PbCl}_{2}$ and $\mathrm{Cu}_{2}\left(\mathrm{NO}_{3}\right)_{2} \cdot 3 \mathrm{H}_{2} \mathrm{O}$ solutions were prepared in DI water, whereas the $\mathrm{As}_{2} \mathrm{O}_{3}$ solution was obtained in $0.2 \mathrm{M} \mathrm{NaOH}$. The $\mathrm{pH}$ values of the metal ion solutions were adjusted by $0.1 \mathrm{M}$ $\mathrm{HNO}_{3}$ or $0.1 \mathrm{M} \mathrm{NaOH}$ solutions. Adsorption studies were performed by adding $0.33 \mathrm{~g} \mathrm{~L}^{-1}$ EDTA-MCS/GO to $30 \mathrm{~mL}$ of each metal ion solution. The initial concentrations of $\mathrm{Pb}^{2+}, \mathrm{Cu}^{2+}$, and $\mathrm{As}^{3+}$ were 50,50 , and $5 \mathrm{mg} \mathrm{L}^{-1}$, respectively. Initial adsorption experiments were performed at $180 \mathrm{rpm}$ and $25^{\circ} \mathrm{C}$ in a shaking incubator. Aliquots were drawn at pre-determined time intervals and the adsorbent was separated using an external magnet. The supernatant was used to analyze the residual metal ion concentrations by inductively coupled plasma optical emission spectroscopy (ICP-OES; Perkin-Elmer Optima 2100 DV). The effects of different operational parameters, such as contact time, solution $\mathrm{pH}$, metal ion concentration, and reaction temperature, were studied to optimize the adsorption efficiency. The adsorption kinetics was investigated at $298 \mathrm{~K}$ with the initial concentrations of the individual metal ions solution as stated above. In order to study adsorption isotherms, experiments were conducted under optimal conditions. The adsorption capacity $\left(q_{\mathrm{e}}\right)$ of the metal ions and removal efficiency (\%) onto EDTA-MCS/GO nanocomposites at the equilibrium stage were calculated using the following equations:

$$
\begin{gathered}
\qquad q_{\mathrm{e}}=\frac{\left(C_{\mathrm{o}}-C_{\mathrm{e}}\right) V}{m} \\
\text { Removal efficiency }(\%)=\frac{\left(C_{\mathrm{o}}-C_{\mathrm{e}}\right)}{C_{\mathrm{o}}} \times 100
\end{gathered}
$$

where $q_{\mathrm{e}}$ is the adsorption capacity $\left(\mathrm{mg} \mathrm{g}^{-1}\right), C_{\mathrm{o}}$ is the initial heavy metal ion concentration in solution $\left(\mathrm{mg} \mathrm{L}^{-1}\right), C_{\mathrm{e}}$ is the equilibrium concentration $\left(\mathrm{mg} \mathrm{L}^{-1}\right)$ after adsorption, $V$ is the solution volume (L), and $m$ is the mass of EDTA-MCS/GO adsorbent (g). Metal ions loaded EDTA-MGC/GO were dissolved separately in $0.1 \mathrm{M} \mathrm{HCl}$ solution and agitated for $5 \mathrm{~h}$ in a shaking incubator at room temperature. After washing several 
times with DI water till pH 6-7, the nanocomposite was dried in an oven and used in successive adsorption-desorption cycles. All the experiments were performed in triplicate and average values were reported.

\section{Results and discussion}

\subsection{Characterization of EDTA-MCS/GO}

The FT-IR results confirmed that EDTA-MCS/GO contained numerous oxygen and nitrogen functional groups (Fig. 1a). A broad band observed at $3430.44 \mathrm{~cm}^{-1}$ was assigned to $\mathrm{O}-\mathrm{H}$ or $\mathrm{N}-\mathrm{H}$ stretching vibrations from adsorbed $\mathrm{H}_{2} \mathrm{O}$ or $-\mathrm{NH}_{2}$ groups of CS on the surface of EDTA-MCS/GO. ${ }^{17}$ The band at 583.54 $\mathrm{cm}^{-1}$ was recognized as $\mathrm{Fe}-\mathrm{O}$ bond stretching of $\mathrm{Fe}_{3} \mathrm{O}_{4}$ in EDTAMCS/GO. ${ }^{18}$ The stretching vibration and bending vibration of the $\mathrm{N}-\mathrm{H}$ bond appeared in a band at $1076.08 \mathrm{~cm}^{-1}$, which was assigned to $-\mathrm{NH}_{2}$ groups in EDTA or CS on the surface of EDTAMCS/GO. Another vibrational band at $1380.64 \mathrm{~cm}^{-1}$ was assigned to $\mathrm{C}-\mathrm{OH} .{ }^{19}$ A strong band at $1630 \mathrm{~cm}^{-1}$ was attributed to $\mathrm{C}=\mathrm{O}$ bond vibrations in carboxyl functional groups. Bands at 2920 and $2845 \mathrm{~cm}^{-1}$ resulted from $\mathrm{C}-\mathrm{H}$ bonds in alkane groups. These $\mathrm{O}$ and $\mathrm{N}$ functional groups could act as available adsorption sites and play important roles in the removal of metal ions from aqueous solutions. ${ }^{12,20,21}$

The crystalline structure of synthesized EDTA-MCS/GO nanocomposites was explained well by the corresponding XRD pattern (Fig. 1b). The GO peak was found at around $2 \theta=10^{\circ}$ in the GO XRD curve. According to the JADE PDF card (89-4319), several sharp and strong diffraction peaks in EDTA-MCS/GO curve, ranging from $2 \theta=30.18-80^{\circ}$ in the XRD crystal lattice planes, were attributed to magnetite. The XRD pattern exhibited a peak at $2 \theta=20.70^{\circ}$, which indicated the amorphous behavior of CS. ${ }^{22}$ A peak around $18.32^{\circ}$ might be evidence of the presence of EDTA. ${ }^{12}$ These several expressive diffraction peaks in the XRD analysis confirmed that the desired product, EDTA-MCS/GO nanocomposite, had been successfully synthesized.

BET analysis was employed to configure the surface area of the nanocomposites. The surface area of the adsorbent plays a key role in adsorption phenomena. The best adsorption capacities should be achieved by large specific surface area of the adsorbent material. The multi-point BET surface area of EDTA-MCS/GO was $81.36 \mathrm{~m}^{2} \mathrm{~g}^{-1}$, which was approximately twice that of previously reported for EDTA-MGO nanocomposites. ${ }^{12}$ This increase in surface area might be due to CS and the newly proposed synthetic method, which made the nanocomposites more suitable for divalent and trivalent ion adsorption. According to IUPAC 1984, the $\mathrm{N}_{2}$ adsorptiondesorption isotherm of EDTA-MCS/GO obeyed a type IV hysteretic loop (Fig. 2a), which demonstrated good adsorbentadsorbate interactions. This high surface area benefitted the adsorption of metal ions.

SEM was performed to investigate the surface morphologies and structures of the EDTA-MCS/GO nanocomposites. The magnified SEM image (Fig. 2b) of GO revealed a sheet-like structure of $\mathrm{sp}^{2}$-hybridized carbon atoms with a smooth surface and crumpled edges. The SEM image in Fig. 2c shows small rounded magnetic chitosan (MCS) particles distributed roughly onto the GO surface. CS was well dispersed with GO and showed a close attachment, which indicated bonding between GO and CS. By adding EDTA, the size of magnetic particles increased. Therefore, comparatively large, rounded magnetic EDTA-CS particles were observed on the surface of the GO sheets (Fig. 2d). Various nano-scale EDTA-MCS particle clusters were widely spread over the surface of the GO sheets. This phenomenon increased the surface availability of the nanocomposites for adsorption and prevented GO agglomeration. ${ }^{2}$ Numerous hydrophilic functional groups, such as $-\mathrm{OH}$ and $-\mathrm{COOH}$, on the GO sheet-like structures were readily available to different chelating moieties. ${ }^{23}$ Therefore, EDTA functional groups and amino groups present in CS could form chemical bonds with the GO sheet surface.

A typical magnetic hysteresis loop of EDTA-MCS/GO was identified in MPMS profile (Fig. S1 $\dagger$ ). At room temperature, the saturation magnetization was $60.84 \mathrm{emu} \mathrm{g}^{-1}$. With almost zero coercivity and zero remanence in the magnetization curve, the synthesized EDTA-MCS/GO nanocomposite showed supermagnetic properties. ${ }^{24}$ The $\mathrm{pH}$ zero point charge $\left(\mathrm{pH}_{\mathrm{zpc}}\right)$ determines the electrophoretic mobility where the net total particle charge is zero. ${ }^{25}$ In zeta potential analysis of EDTA-MCS/GO, the $\mathrm{pH}_{\mathrm{zpc}}$ value was 3.8 and the composite was negatively charged after pH 3.8 (Fig. S2†).

\subsection{Metal ion adsorption}

3.2.1. Effect of solution $\mathrm{pH}$, contact time, temperature, and initial metal concentration. In water/wastewater treatment, $\mathrm{pH}$
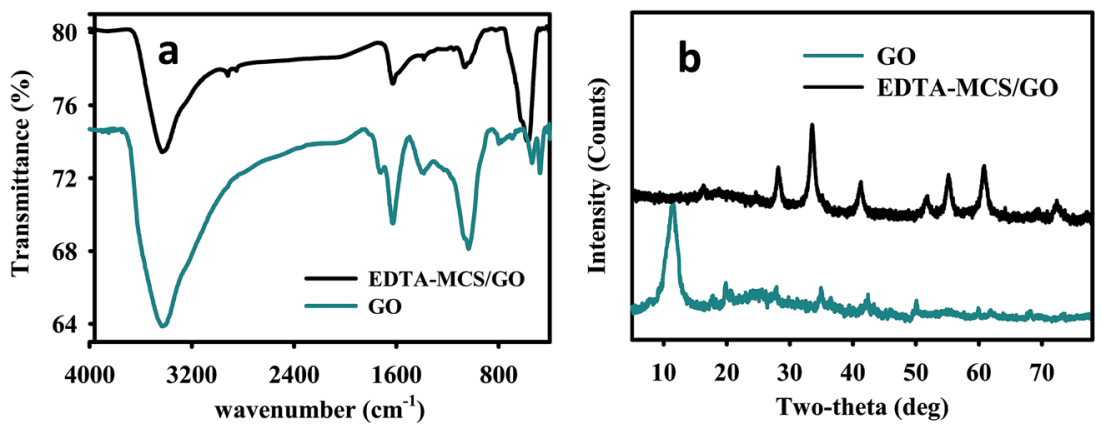

Fig. 1 (a) FT-IR spectra and (b) XRD patterns of GO and EDTA-MCS/GO nanocomposites. 
is a key operational parameter, as it can influence both the adsorbent structure and the distribution of pollutant species. Therefore, the effect of $\mathrm{pH}$ was studied in the removal of metal ions from aqueous solution using the synthesized adsorbent. The uptake efficiency in the $\mathrm{pH}$ range was examined with initial concentrations of $50 \mathrm{mg} \mathrm{L}^{-1}$ for $\mathrm{Pb}^{2+}$ and $\mathrm{Cu}^{2+}$, and $5 \mathrm{mg} \mathrm{L}^{-1}$ for $\mathrm{As}^{3+}$. Metal ion adsorption onto the EDTA-MCS/GO nanocomposite was strongly dependent upon the initial $\mathrm{pH}$. An increase in $\mathrm{Pb}^{2+}$ removal was noted with increasing $\mathrm{pH}$ up to 5.0, while a sudden decrease in adsorption was observed at higher $\mathrm{pH}$ values, as shown in Fig. $\mathrm{S} 3 . \dagger \mathrm{Cu}^{2+}$ removal increased gradually with increasing $\mathrm{pH}$, with maximum adsorption occurring at $\mathrm{pH} 5.5$ (Fig. $\mathrm{S} 3 \dagger$ ), but $\mathrm{pH} 8.0$ was found to be optimal pH for $\mathrm{As}^{3+}$ adsorption (Fig. 4a). Adsorption densities of 134.82, 119.91, and $11.50 \mathrm{mg} \mathrm{g}^{-1}$ were obtained for $\mathrm{Pb}^{2+}, \mathrm{Cu}^{2+}$, and $\mathrm{As}^{3+}$, respectively, at the corresponding optimum $\mathrm{pH}$. In the removal of all cationic metal ions, the adsorption capacities were highest at higher $\mathrm{pH}$ values, and vice versa. A $\mathrm{pH}$ value $>5.0$ was reported to be favorable for the removal of different cationic metal ion by GO-based adsorbents. ${ }^{26}$ The EDTA-MCS/GO surface contained hydrophilic functional groups $(-\mathrm{OH}$, $-\mathrm{COOH}$, and $-\mathrm{NH}_{2}$ ), so at lower $\mathrm{pH}$ values, the nanocomposites became positively charged due to protonation, with electrostatic repulsion causing weak bonding between cationic metals ions and the adsorbent. By increasing the $\mathrm{pH}$, the charges on the adsorbent surface $\left(\mathrm{H}_{3} \mathrm{O}^{+}\right)$became weaker, and competition between $\mathrm{H}_{3} \mathrm{O}^{+}$and the metal ions might occur. This phenomenon could cause an increase in the electrostatic attraction of the positively charged metal ions to the nanocomposite surface. ${ }^{27,28}$ Moreover, in zeta potential analysis $\mathrm{pH}_{\mathrm{zpc}}$ was about 3.8 and positive zeta potential values were measured below $\mathrm{pH}_{\text {zpc }}$, proving $\mathrm{H}^{+}$competition upon adsorbent-adsorbate interaction. Therefore, at higher $\mathrm{pH}(\mathrm{pH}>3.8)$ the nanocomposite surface was negatively charged, which increased the adsorption of positively charged metal ions. Therefore, optimum $\mathrm{pH}$ values of $5,5.5$, and 8.0 were chosen for further experiments involving $\mathrm{Pb}^{2+}, \mathrm{Cu}^{2+}$, and $\mathrm{As}^{3+}$, respectively.

The adsorption of metal ions on the EDTA-MCS/GO nanocomposite increased with increasing contact time, and an equilibrium was reached within $5 \mathrm{~h}$ for $\mathrm{Pb}^{2+}$ and $\mathrm{Cu}^{2+}$, and $11 \mathrm{~h}$ for $\mathrm{As}^{3+}$. The metal removal rate at the initial contact time was high, which could be attributed to the large number of vacant binding sites available for metal ion adsorption to the nanocomposite surfaces. As the exterior surface became exhausted, the adsorbate uptake rate began to decrease, eventually reaching an apparent equilibrium. A fast adsorption process was observed for $\mathrm{Pb}^{2+}$ and $\mathrm{Cu}^{2+}$ metal ions, which might be due to the strong chemical bonding between metals ions and oxygenated groups in the EDTA-MCS/GO nanocomposites. In contrast, the $\mathrm{As}^{3+}$ adsorption equilibrium was established more slowly, which could be sign of poor bonding interactions (compared with $\mathrm{Pb}^{2+}$ and $\mathrm{Cu}^{2+}$ ) between the adsorbent and adsorbate. Furthermore, EDTA is a hard ligand, so its functional groups easily form strong bonds with hard metals, such as $\mathrm{Pb}^{2+}$ and $\mathrm{Cu}^{2+}$, but comparatively weak bonds with soft transition metals, such as $\mathrm{As}^{3+} .{ }^{29}$ Nevertheless, $\mathrm{As}^{3+}$ adsorption efficiency was still very good, which might be due to the presence of CS in EDTAMCS/GO. The heterogeneous adsorbent surface might cause the variation in bonding interactions among the different metal ions.

The initial metal ion concentrations had a significant effect on their removal from aqueous solutions. The adsorption densities of $\mathrm{Pb}^{2+}$ and $\mathrm{Cu}^{2+}$ on the nanocomposite increased from 26.62 and 27.12 to 209.49 and $195.57 \mathrm{mg} \mathrm{g}^{-1}$, respectively,
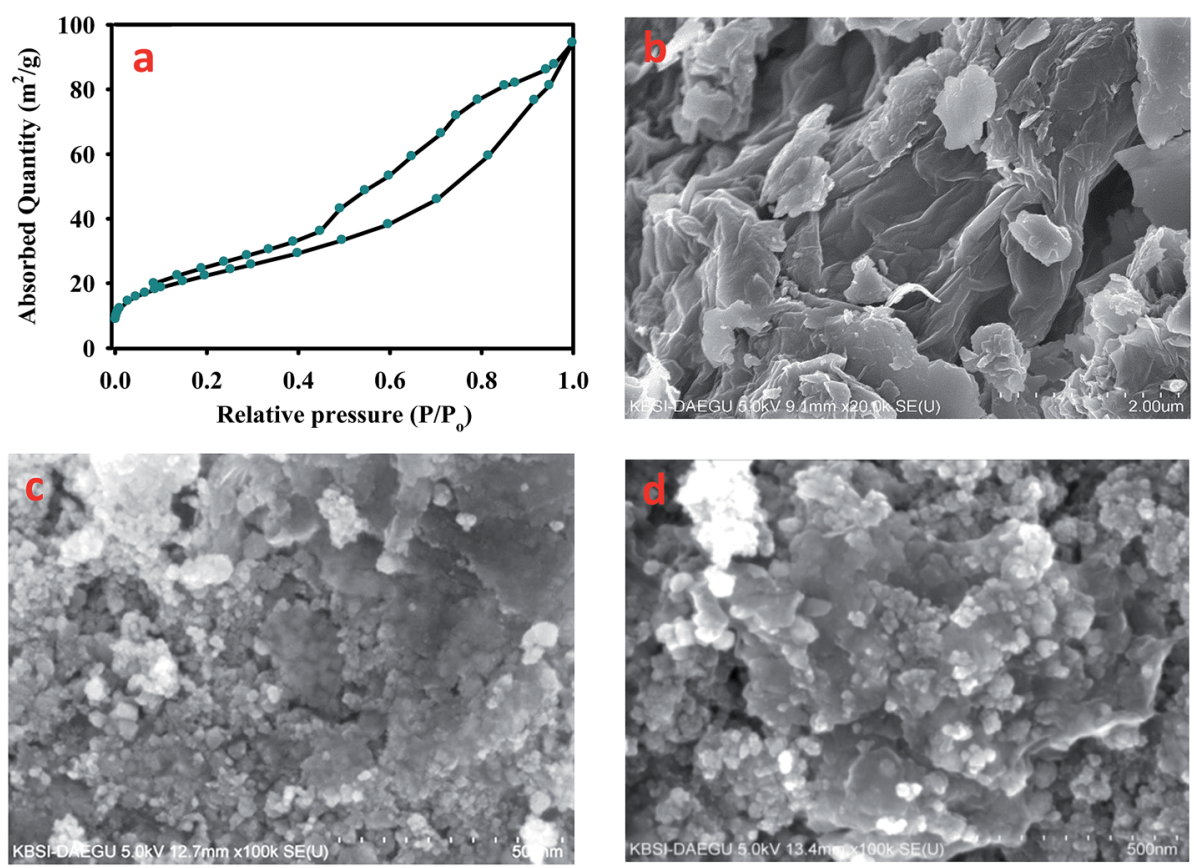

Fig. 2 (a) BET analysis of EDTA-MCS/GO nanocomposites with nitrogen adsorption and SEM images of (b) GO, (c) MCS/GO, and (d) EDTA-MCS/ GO nanocomposites. 

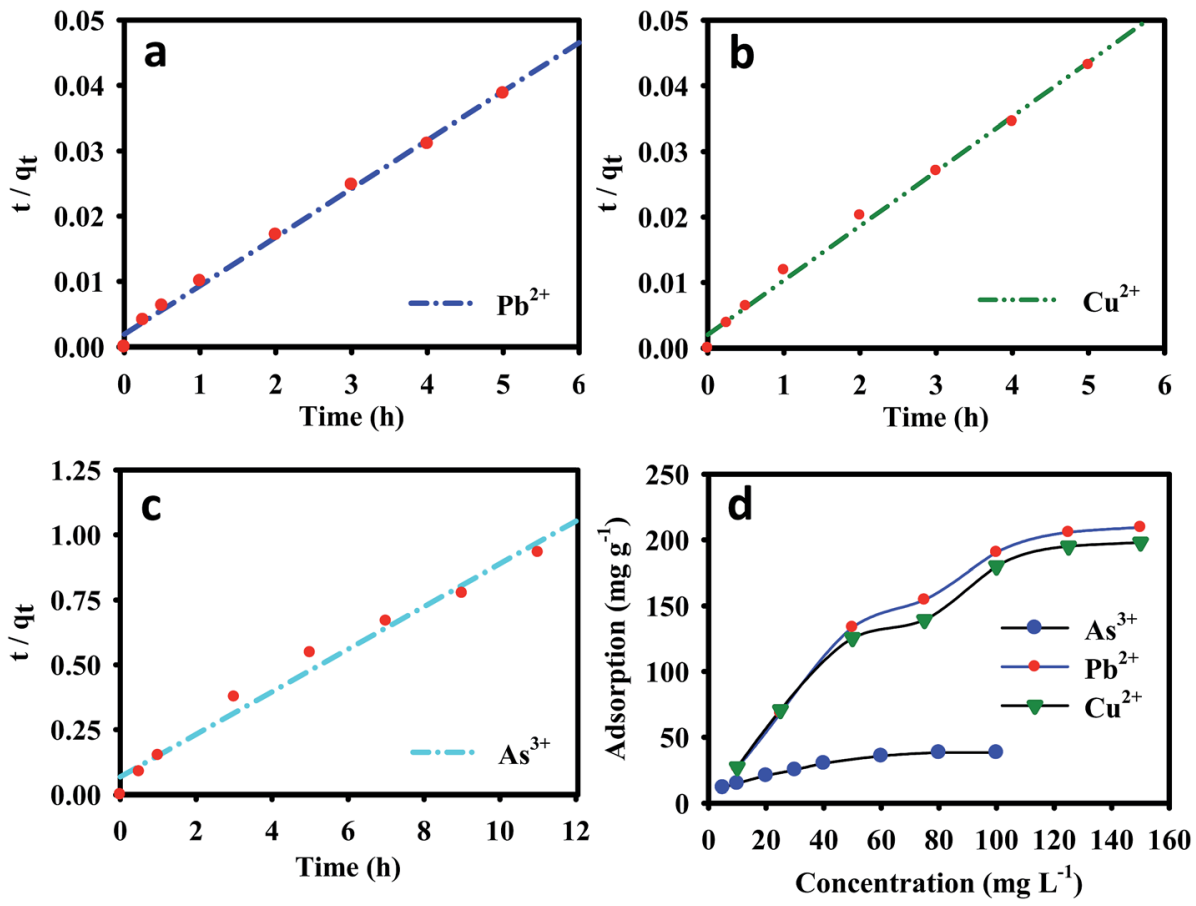

Fig. 3 Pseudo-second-order curve-fitting graphs of (a) $\mathrm{Pb}^{2+}$, (b) $\mathrm{Cu}^{2+}$, and (c) $\mathrm{As}^{3+}$ at $298.15 \mathrm{~K}$. (d) Adsorption profiles of $\mathrm{Pb}^{2+}, \mathrm{Cu}^{2+}$, and $\mathrm{As}^{3+} \mathrm{On}^{2}$ EDTA-MCS/GO nanocomposite at different metal ion concentrations.

with increase in the initial metal ion concentration was increased from 10 to $150 \mathrm{mg} \mathrm{L}^{-1}$. Similarly, the nanocomposite $\mathrm{As}^{3+}$ adsorption capacity increased from 11.50 to $38.24 \mathrm{mg} \mathrm{g}^{-1}$ when the initial $\mathrm{As}^{3+}$ concentration was increased from 5 to $100 \mathrm{mg} \mathrm{L}^{-1}$ (Fig. 3). Higher initial metal ion concentrations resulted in higher mass gradient pressures between the aqueous solution and nanocomposite, which may provide a driving force to overcome the mass transfer resistance between the aqueous and solid phases.

To determine the effect of temperature on the metal ion adsorption by the EDTA-MCS/GO nanocomposites, experiments were carried out at 298,303 , and $313 \mathrm{~K}$ while keeping all the other parameters, such as the concentrations of adsorbate and adsorbent, $\mathrm{pH}$, and agitation speed, constant. The $\mathrm{Pb}^{2+}$ and $\mathrm{Cu}^{2+}$ adsorption densities decreased significantly from 134.82 and $95.91 \mathrm{mg} \mathrm{g}^{-1}$ to 119.91 and $60.6 \mathrm{mg} \mathrm{g}^{-1}$, respectively, as the temperature increased from 298 to $313 \mathrm{~K}$, using an initial metal concentration of $50 \mathrm{ppm}$. In contrast, a slight increase in adsorption, from 11.50 to $11.96 \mathrm{mg} \mathrm{g}^{-1}$ was observed for $\mathrm{As}^{3+}$ with the temperature increase from 298 to $313 \mathrm{~K}$. These results showed that $\mathrm{Pb}^{2+}$ and $\mathrm{Cu}^{2+}$ adsorption on the EDTA-MCS/GO nanocomposite were exothermic processes, while $\mathrm{As}^{3+}$ adsorption might be slightly endothermic. Therefore, metal ion adsorption by the EDTA-MCS/GO nanocomposite was significantly affected by temperature.

3.2.2. Adsorption kinetics. The adsorption kinetics for $\mathrm{Pb}^{2+}, \mathrm{Cu}^{2+}$, and $\mathrm{As}^{3+}$ removal were analyzed using Lagergren's pseudo-first-order (3) and pseudo-second-order kinetics models (4):

$$
\begin{array}{r}
\ln \left(q_{\mathrm{e}}-q_{t}\right)=\ln q_{\mathrm{e}}-k_{1} t \\
\frac{t}{q_{t}}=\frac{1}{k_{2} q_{\mathrm{e}}^{2}}+\frac{t}{q_{\mathrm{e}}}
\end{array}
$$

where $q_{t}$ is the metal ion concentration $\left(\mathrm{mg} \mathrm{g}^{-1}\right)$ at any given time $(t), q_{\mathrm{e}}$ is the metal ion equilibrium concentration, $k_{1}$ is the first-order rate constant $\left(\mathrm{h}^{-1}\right)$, and $k_{2}$ is the second-order rate constant $\left(\mathrm{g} \mathrm{mg}^{-1} \mathrm{~h}^{-1}\right)$. Table 1 depicts the kinetics parameters obtained from these two kinetic models. Lagergren's pseudofirst-order model did not fit the entire range of the adsorption process well and was only applicable over the initial contact times (Fig. S4†). The values of the regression coefficients were

\begin{tabular}{|c|c|c|c|c|c|c|c|}
\hline \multirow[b]{2}{*}{ Target pollutant } & \multicolumn{3}{|c|}{$1^{\text {st }}$ order } & \multicolumn{3}{|c|}{$2^{\text {nd }}$ order } & \multirow{2}{*}{$\begin{array}{l}\text { Experimental } \\
q_{\mathrm{e}}\end{array}$} \\
\hline & $q_{\mathrm{e}}$ & $K_{1}$ & $r^{2}$ & $q_{\mathrm{e}}$ & $K_{2}$ & $r^{2}$ & \\
\hline $\mathrm{Cu}^{2+}$ & 92.57 & 1.241 & 0.731 & 120.48 & 0.0000083 & 0.994 & 119.91 \\
\hline $\mathrm{As}^{3+}$ & 8.19 & 0.207 & 0.771 & 12.18 & 0.60996 & 0.980 & 11.50 \\
\hline
\end{tabular}

Table 1 Pseudo-first- and second-order rate constants for $\mathrm{Pb}^{2+}, \mathrm{Cu}^{2+}$, and $\mathrm{As}^{3+}$ adsorption onto EDTA-MCS/GO at pH 5, 5.5, and 8, respectively 

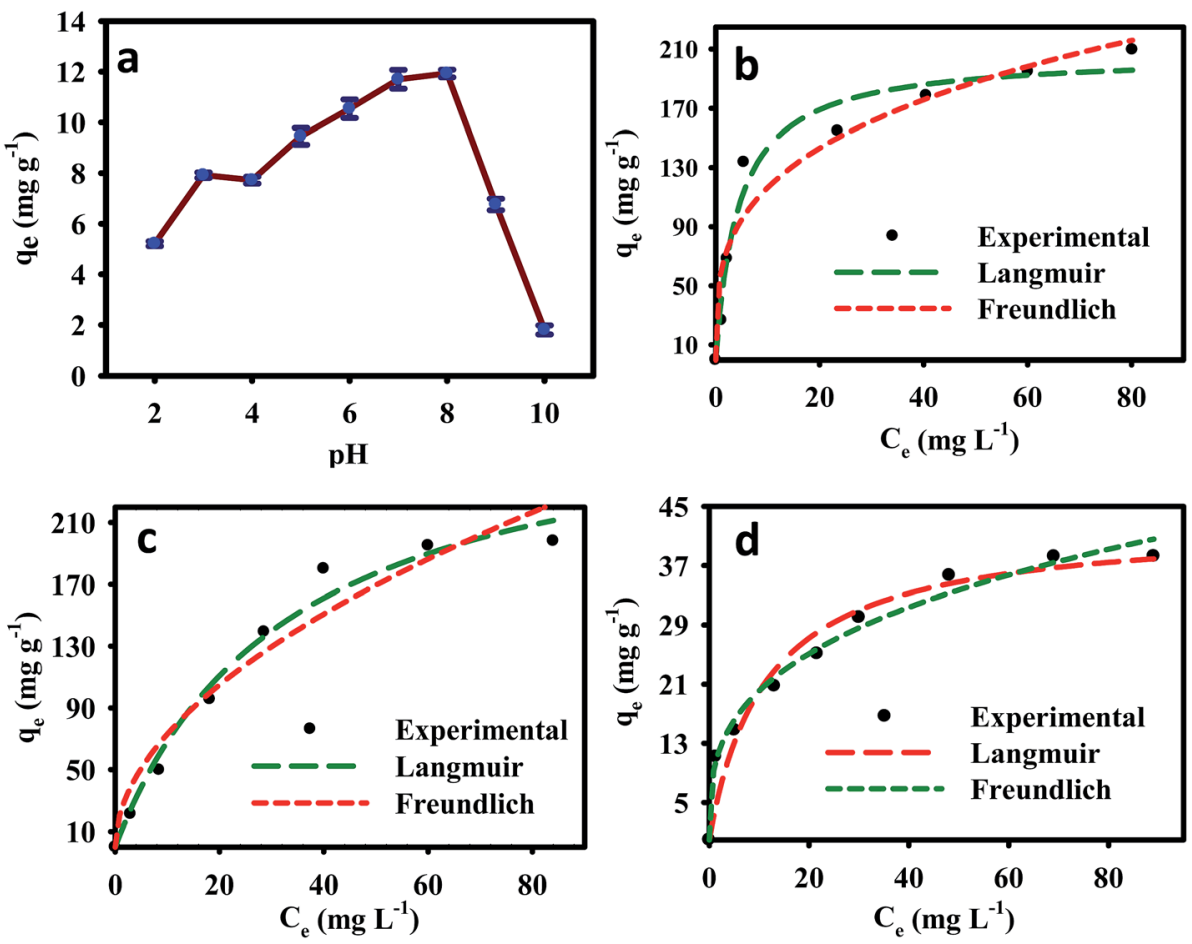

Fig. 4 (a) Effect of $\mathrm{pH}$ on $\mathrm{As}^{3+}$ removal and (b-d) adsorption isotherm model fits for $\mathrm{Pb}^{2+}, \mathrm{Cu}^{2+}$, and $\mathrm{As}^{3+}$ adsorption onto EDTA-MCS/GO.

quite low $\left(r^{2}=0.891,0.731\right.$, and 0.771 for $\mathrm{Pb}^{2+}, \mathrm{Cu}^{2+}$, and $\mathrm{As}^{3+}$, respectively) and the experimental $q_{\mathrm{e}}$ values were in good agreement with the theoretical values calculated by the pseudosecond-order equation. The pseudo-second-order kinetic model provided better correlation with the adsorption of metal ions on the EDTA-MCS/GO nanocomposites, with higher $r^{2}$ values (0.996, 0.994, and 0.980 for $\mathrm{Pb}^{2+}, \mathrm{Cu}^{2+}$, and $\mathrm{As}^{3+}$, respectively) compared with the pseudo-first-order model. Moreover, the calculated adsorption capacities from the pseudo-second-order equations were near the experimental values. The pseudosecond-order model gave the best fit for the chemical interactions between the nanocomposite functional groups and the adsorbed $\mathrm{Pb}^{2+}, \mathrm{Cu}^{2+}$, and $\mathrm{As}^{3}$ metal ions, and the adsorption process was concluded to involve chemisorption and to be the rate-limiting step (Fig. 3).

3.2.3. Adsorption isotherms. The metal ion adsorption isotherms of EDTA-MCS/GO were studied at different metal ion concentrations, while keeping all the other parameters constant. The maximum adsorption densities of $\mathrm{Pb}^{2+}, \mathrm{Cu}^{2+}$, and $\mathrm{As}^{3+}$ on the synthesized EDTA-MCS/GO nanocomposites were $209.49,195.57$, and $38.23 \mathrm{mg} \mathrm{g}^{-1}$, respectively (Fig. 3d). These adsorption capacities $\left(q_{\mathrm{e}}\right)$ for both divalent and trivalent metal ions were achieved using very small amounts of adsorbent $\left(0.33 \mathrm{~g} \mathrm{~L} \mathrm{~L}^{-1}\right)$. The synthesized adsorbent presented excellent sorption behavior towards heavy metal ions. Sorption isotherm models were used to analyze the nature of adsorbent-adsorbate interactions at equilibrium stages and determine the maximum heavy metal ion adsorption capacities of the synthesized nanocomposites. In this study, we used two equilibrium models to examine the experimental data: the Langmuir model (5),

$$
q_{\mathrm{e}}=\frac{q_{\max } K_{\mathrm{L}} C_{\mathrm{e}}}{1+K_{\mathrm{L}} C_{\mathrm{e}}}
$$

where $q_{\max }\left(\mathrm{mg} \mathrm{g}^{-1}\right)$ is the maximum adsorption capacity of the adsorbent, and $K_{\mathrm{L}}\left(\mathrm{L} \mathrm{mg}^{-1}\right)$ is the Langmuir sorption constant related to the free energy of adsorption; and the Freundlich model (6),

$$
q_{\mathrm{e}}=K_{\mathrm{f}} C_{\mathrm{e}}^{1 / n}
$$

Table 2 Adsorption parameters of Langmuir and Freundlich adsorption isotherm models for $\mathrm{Pb}^{2+}, \mathrm{Cu}^{2+}$, and As ${ }^{3+}$ adsorption onto EDTA-MCS/ GO

\begin{tabular}{lllllll}
\hline & \multicolumn{2}{l}{ Langmuir } & & \multicolumn{2}{c}{ Freundlich } \\
\cline { 2 - 3 } Target pollutant & $q_{\max }\left(\mathrm{mg} \mathrm{g}^{-1}\right)$ & $k_{\mathrm{L}}$ & $r^{2}$ & & $k_{\mathrm{F}}\left(\mathrm{mg} \mathrm{g}^{-1}\right)$ & $1 / n$ \\
\hline $\mathrm{Pb}^{2+}$ & 206.52 & 0.23 & 0.967 & 58.73 & 0.297 & $r^{2}$ \\
$\mathrm{Cu}^{2+}$ & 207.26 & 0.19 & 0.971 & 59.41 & 0.931 \\
$\mathrm{As}^{3+}$ & 42.75 & 0.09 & 0.946 & 9.60 & 0.941 \\
& & & & 0.985
\end{tabular}


Table 3 Comparison of metal ions adsorption onto EDTA-MCS/GO with other carbonaceous nano-adsorbents

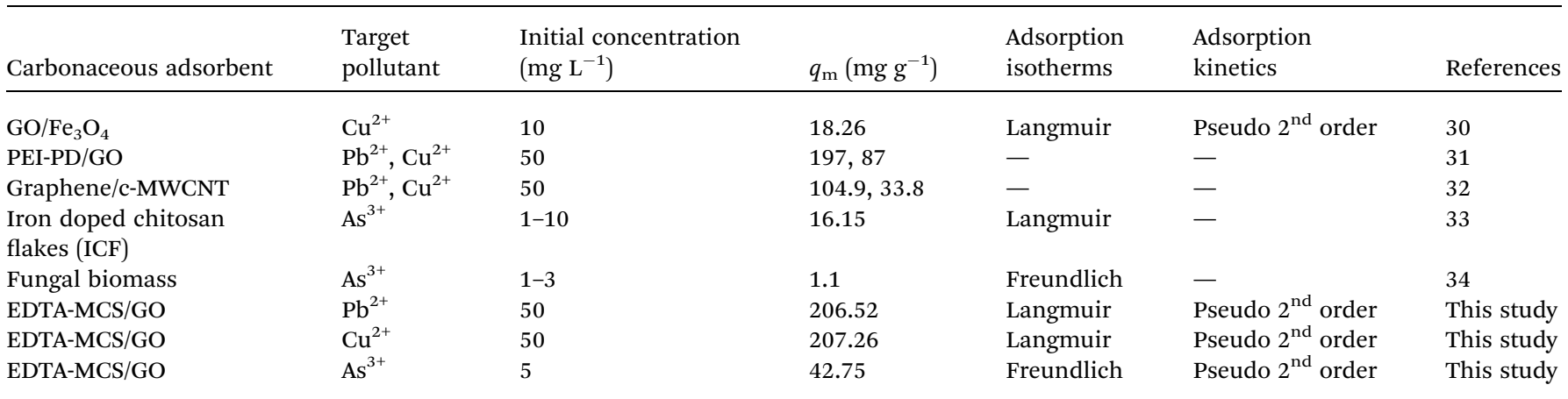

where $K_{\mathrm{f}}\left(\mathrm{L} \mathrm{g}^{-1}\right)$ and $n$ (dimensionless) are isotherm constants.

The experimental results, together with the non-linear Langmuir and Freundlich fits for $\mathrm{Pb}^{2+}, \mathrm{Cu}^{2+}$, and $\mathrm{As}^{3+}$, are plotted in Fig. 4b-d, respectively, and the isotherms parameters are summarized in Table 2. The $\mathrm{Pb}^{2+}$ and $\mathrm{Cu}^{2+}$ experimental data showed best fits for Langmuir isotherms because its regression coefficients $\left(r^{2}=0.967\right.$ and 0.971$)$ were higher than those of the Freundlich isotherm model $\left(r^{2}=0.931\right.$ and 0.941$)$. The adsorption of $\mathrm{Pb}^{2+}$ and $\mathrm{Cu}^{2+}$ was typically monomolecular layer adsorption. Furthermore, the maximum calculated amounts of adsorbed metal ions $\left(q_{\max }\right)$ from the Langmuir isotherm were 206.52, 207.26, and $42.75 \mathrm{mg} \mathrm{g}^{-1}$ for $\mathrm{Pb}^{2+}, \mathrm{Cu}^{2+}$, and $\mathrm{As}^{3+}$ respectively. The regression coefficient of the Freundlich isotherm model for $\mathrm{As}^{3+}\left(r^{2}=0.985\right)$ was higher than that of the Langmuir isotherm model, which suggested that $\mathrm{As}^{3+}$ adsorption onto the EDTA-MCS/GO nanocomposites formed a monolayer on the heterogeneous adsorbent surface.

3.2.4. Reusability of EDTA-MCS/GO. The desorption capability of the synthesized nanocomposites was evaluated. Once an adsorption equilibrium achieved, the used nanocomposites were desorbed in acidic solution. The nanocomposites was reused in four adsorption-desorption cycles as can be seen in Fig. S5. $\dagger$ A small decreasing trend in all metal ions adsorption capacity was noticed in the adsorption-desorption cycles (Fig. S5†). Meanwhile, after four adsorption-desorption cycles, the EDTA-MCS/ GO nanocomposite showed high magnetic sensitivity under an external magnetic field. The results showed that the synthesized nanocomposite can be used as a potentially good adsorbent to remove $\mathrm{Pb}^{2+}, \mathrm{Cu}^{2+}$, and $\mathrm{As}^{3+}$ simultaneously in aqueous solution.

3.2.5. Real wastewater assessment. The adsorbent performance of EDTA-MCS/GO in a real wastewater was investigated. The wastewater sample was taken from a domestic wastewater treatment plant. In Table $\mathrm{S} 1 \uparrow$ the chemical composition of wastewater is summarized. Then a known concentration of $\mathrm{Pb}^{2+}, \mathrm{Cu}^{2+}$, and $\mathrm{As}^{3+}$ ions were dissolved in the wastewater sample with the fixed amount of adsorbent $\left(0.03 \mathrm{~g} \mathrm{~L}^{-1}\right)$. The adsorption process was continued for $24 \mathrm{~h}$ under an optimized condition. The maximum adsorption capacities of $\mathrm{Pb}^{2+}, \mathrm{Cu}^{2+}$, and $\mathrm{As}^{3+}$ were $116.16,102.6$, and $8.82 \mathrm{mg} \mathrm{g}^{-1}$, respectively, which were $87.20,86.77$, and $80.39 \%$ of those in deionized water. The decrease of sorption capacities of heavy metal ions in domestic wastewater compared with those in deionized water may be caused by the increase of ionic strength in wastewater.
The presence of anions such as sulfate, phosphate, chloride, and nitrate was also observed in wastewater (as shown in Table $\mathrm{S} 1 \dagger)$. These interfering anions might cause a decrease in metal ions adsorption capacity of EDTA-MCS/GO.

3.2.6. Adsorption evaluation. There are several adsorbents that could contribute to heavy metal removal from wastewater. EDTA-MCS/GO nanocomposite could be an important new adsorbent among recent advanced adsorbents developed for water/wastewater treatment systems. Using the minimum amount $\left(0.33 \mathrm{~g} \mathrm{~L}^{-1}\right)$ of sorbent, we achieved $q_{\max }$ values of 206.52, 207.26, and $42.75 \mathrm{mg} \mathrm{g}{ }^{-1}$ for $\mathrm{Pb}^{2+}, \mathrm{Cu}^{2+}$, and $\mathrm{As}^{3+}$, respectively, which might be due to the conglomeration of EDTA, GO, and CS properties in a single composite. The adsorption capacities for metal ions removal in this study were much higher than those of many conventional and recently reported graphene-based adsorbents. ${ }^{26} \mathrm{~A}$ comparison of different types of adsorbent with the synthesized EDTA-MCS/ GO nanocomposite for their removal capabilities, adsorption isotherms, and adsorption kinetics is shown in Table 3.

\section{Conclusion}

This work demonstrated the efficient removal of divalent $\left(\mathrm{Pb}^{2+}\right.$ and $\left.\mathrm{Cu}^{2+}\right)$ and trivalent $\left(\mathrm{As}^{3+}\right)$ metal ions using EDTA-MCS/GO nanocomposite. The synthesized nanomaterial was characterized by SEM, FT-IR, MPMS, XRD, and zeta potential analyses. The pseudo-second-order kinetic model gave better correlation with the adsorptions of all the three metal ions than the pseudo-firstorder one. Langmuir isotherms were the best fits for $\mathrm{Pb}^{2+}$ and $\mathrm{Cu}^{2+}$ adsorption, while the $\mathrm{As}^{3+}$ adsorption process was well described by its Freundlich isotherm. A chemical adsorption process of individual metal ions was suggested by kinetics and isotherm results. The synthesized nanocomposite exhibited a good regeneration capacity towards target metal ions after four successive adsorption-desorption cycles. Efficient removal of metal ions in real wastewater was also achieved. Therefore, EDTAMCS/GO nanocomposite is a promising adsorbent for $\mathrm{Pb}^{2+}, \mathrm{Cu}^{2+}$, and $\mathrm{As}^{3+}$ removal from contaminated water/wastewater.

\section{Acknowledgements}

This work was supported by a grant provided by the Human Resource Training Program for Regional Innovation and Creativity 
through the Ministry of Education (ME) and National Research Foundation (NRF) of Korea (NRF-2014H1C1A1066929). This study was also supported by grants (NRF-2016R1A2B4010431) through the ME and NRF of Korea. Additionally, this research was supported by an NRF grant from the Korean government (MSIP) (NRF2015M2A7A1000194).

\section{References}

1 F. Fu and Q. Wang, J. Environ. Manage., 2011, 92, 407-418.

2 X. Li, H. Zhou, W. Wu, S. Wei, Y. Xu and Y. Kuang, J. Colloid Interface Sci., 2015, 448, 389-397.

3 S. Muhammad, M. T. Shah and S. Khan, Microchem. J., 2011, 98, 334-343.

4 C. Abourached, T. Catal and H. Liu, Water Res., 2014, 51, 228-233.

5 R. Naseem and S. S. Tahir, Water Res., 2001, 35, 3982-3986. 6 A. T. Paulino, F. A. S. Minasse, M. R. Guilherme, A. V. Reis, E. C. Muniz and J. Nozaki, J. Colloid Interface Sci., 2006, 301, 479-487.

7 D. Mohan and C. U. Pittman, J. Hazard. Mater., 2007, 142, 153.

8 T. S. Y. Choong, T. G. Chuah, Y. Robiah, F. L. Gregory Koay and I. Azni, Desalination, 2007, 217, 139-166.

9 Y. Zhang, L. Yan, W. Xu, X. Guo, L. Cui, L. Gao, Q. Wei and B. Du, J. Mol. Liq., 2014, 191, 177-182.

10 J. Hur, J. Shin, J. Yoo and Y. Seo, Sci. World J., 2015, 2015, 111.

11 A. E. Galashev and V. A. Polukhin, Phys. Met. Metallogr., 2014, 115, 697-704.

12 L. Cui, Y. Wang, L. Gao, L. Hu, L. Yan, Q. Wei and B. Du, Chem. Eng. J., 2015, 281, 1-10.

13 E. Repo, R. Koivula, R. Harjula and M. Sillanpää, Desalination, 2013, 321, 93-102.

14 C. Cao, L. Xiao, C. Chen, X. Shi, Q. Cao and L. Gao, Powder Technol., 2014, 260, 90-97.

15 A. A. Kadam and D. S. Lee, Bioresour. Technol., 2015, 193, 563-567.

16 W. S. J. Hummers and R. E. Offeman, J. Am. Chem. Soc., 1958, 80, 1339.
17 R. Extremera, I. Pavlovic, M. R. Pérez and C. Barriga, Chem. Eng. J., 2012, 213, 392-400.

18 L. Ai, C. Zhang and Z. Chen, J. Hazard. Mater., 2011, 192, 1515-1524.

19 R. R. Shan, L. G. Yan, K. Yang, S. J. Yu, Y. F. Hao, H. Q. Yu and B. Du, Chem. Eng. J., 2014, 252, 38-46.

20 J. H. Deng, X. R. Zhang, G. M. Zeng, J. L. Gong, Q. Y. Niu and J. Liang, Chem. Eng. J., 2013, 226, 189-200.

21 L. Dambies, T. Vincent and E. Guibal, Water Res., 2002, 36, 3699-3710.

22 S. F. Wang, L. Shen, W. De Zhang and Y. J. Tong, Biomacromolecules, 2005, 6, 3067-3072.

23 H. Guo, T. Jiao, Q. Zhang, W. Guo, Q. Peng and X. Yan, Nanoscale Res. Lett., 2015, 10, 1-10.

24 S. Sheshmani, A. Ashori and S. Hasanzadeh, Int. J. Biol. Macromol., 2014, 68, 218-224.

25 X. Guo, B. Du, Q. Wei, J. Yang, L. Hu, L. Yan and W. Xu, J. Hazard. Mater., 2014, 278, 211-220.

26 M. Yusuf, F. M. Elfghi, S. A. Zaidi, E. C. Abdullah and M. A. Khan, RSC Adv., 2015, 5, 50392-50420.

27 H. T. Xing, J. H. Chen, X. Sun, Y. H. Huang, Z. B. Su, S. R. Hu, W. Weng, S. X. Li, H. X. Guo, W. B. Wu, Y. S. He, F. M. Li and Y. Huang, Chem. Eng. J., 2015, 263, 280-289.

28 I. A. H. Schneider and J. Rubio, Environ. Sci. Technol., 1999, 33, 2213-2217.

29 W. Yantasee, R. D. Rutledge, W. Chouyyok, V. Sukwarotwat, G. Orr, C. L. Warner, M. G. Warner, G. E. Fryxell, R. J. Wiacek, C. Timchalk and R. S. Addleman, ACS Appl. Mater. Interfaces, 2010, 2, 2749-2758.

30 J. Li, S. Zhang, C. Chen, G. Zhao, X. Yang, J. Li and X. Wang, ACS Appl. Mater. Interfaces, 2012, 4, 4991-5000.

31 Z. Dong, F. Zhang, D. Wang, X. Liu and J. Jin, J. Solid State Chem., 2015, 224, 88-93.

32 Z. Sui, Q. Meng, X. Zhang, R. Ma and B. Cao, J. Mater. Chem., 2012, 22, 8767-8771.

33 A. Gupta, V. S. Chauhan and N. Sankararamakrishnan, Water Res., 2009, 43, 3862-3870.

34 G. S. Murugesan, M. Sathishkumar and K. Swaminathan, Bioresour. Technol., 2006, 97, 483-487. 